\title{
Social scientists in public health: a fuzzy approach
}

Juliana Luporini do Nascimento ${ }^{1}$

Celso Stephan ${ }^{1}$

Everardo Duarte Nunes ${ }^{1}$

${ }^{1}$ Faculdade de Ciências Médicas, UNICAMP. Cidade Universitária Zeferino Vaz, Distrito de Barão Geraldo. 13083-970 Campinas SP Brasil.

jluporini10@hotmail.com
Abstract This study aims to describe and analyze the presence of social scientists, anthropologists, sociologists and political scientists in the field of public health. A survey by the Lattes Curriculum and sites of Medical Colleges, Institutes of Health Research Collective, seeking professionals who work in healthcare and have done some stage of their training in the areas of social sciences. In confluence with Norbert Elias' concepts of social networks and configuration of interdependence it was used fuzzy logic, and the tool free statistical software $R$ version 2.12 .0 which enabled a graphic representation of social scientists interdependence in the field of social sciences-health-social sciences. A total of 238 professionals were ready in 6 distinct clusters according to the distance or closer of each professional in relation to public health and social sciences. The work was shown with great analytical and graphical representation possibilities for social sciences of health, in using this innovative quantitative methodology.

Key words Social scientists of health, Public health, Fuzzy logic, Figuration, Social networks 
[...] the social realm is grey but science is black and white. Thus, bivalent thinking is not per se adequate to cope with social

phenomena.

(Winter and Kron ${ }^{1}$ )

\section{Introduction}

Since we decided on social scientists who work in collective health as research object of this study, we knew we would face a double problem: First, dispersion of what is considered as social scientists and collective health. Second, how to set out approximations and dispersions between social scientists and the collective health field. We are aware that, to understand "the so-called social sciences", using the title of Bomeny and Birman's book $^{2}$, we need to pay attention to some divisions, such as, for instance, starting from formation trajectory, in other words, the undergraduate and graduate degrees of the lato sensu social scientists and those degrees that are fragmented between sociologists, anthropologists and political scientists. On the other hand, there was the collective health field, which traditionally is divided into social sciences in health, epidemiology and health planning and management. Coping is not over in such complex relationships network, which gradually has been structuring throughout the history of Brazilian collective health and gets stronger in as much as the professionals get closer to the field, given its multi professional characteristic, which come from different knowledge areas and, even being social scientists, they walk through different paths in terms of their education. Facing the challenge to understand the way the professionals are grouped according to their academic background and approaching or distancing themselves from social sciences and collective health, we had to make a methodological option for this study. Actually, we realized that our problem was worsening as we were handling our data bank - Lattes website by $\mathrm{CNPq}$ - and it became more cloudy and full of uncertainties. Undoubtedly, those two words - cloudy and uncertainties - started to show us an uncommon methodology in our area - social sciences in health - the fuzzy logics. Thus, we defined that the main objective of this article was to explore the methodological potentialities of using fuzzy logics to graphically visualize and understand the field formation of professionals with undergraduate and/or graduate education in the areas of social sciences working in health area.

\section{A confluence: Elias and fuzzy logics}

As cited above, we had a double challenge: Social sciences and collective health as structures, but structuring the habits of their agents. We needed a sociological reference that assured us a theoretical approximation with our objectives. Certainly, it first occurred to us the famous notions by Pierre Bourdieu - field/habitus, however we considered that Norbert Elias and his notions of configuration/habitus would provide us the conceptual strength to illuminate the theoretical construction of our research. It seemed that those two notions represent a wide range of possibilities that apply to understanding of social sciences and collective health. To Corcuff ${ }^{3}$, both Bourdieu and Elias and also Anthony Giddens are sociologists that are dedicated to "look for passages between the objective and subjective or collective and individual" and kept "giving certain predominance to social structures and macro social aspects of reality, integrating in a variable way, the subjective and interaction dimensions". According to Corcuff ${ }^{3}$, "The criticism to classical opposition between individuals and society is one of Norbert Elias' bases of work". It must be added that the sociological theory that Elias prepared conceives his task as analyzing the social procedures grounded on individuals' activities who, through their basic provisions, in other words, their necessities, are guided one to others and united in the most different ways ${ }^{4,5}$. When we extend such notions to social sciences in general, we do not loose Elias' perspective when we adopt the following definition of Social Sciences as "A Group of subjects that attempt, in a objective way, to study social systems and structures, political and economical processes, the interactions of different groups or individuals with the purpose to ground a knowledge corpus that can be identified ${ }^{6}$ (emphasis added).

When thinking about social sciences in health as a configuration, we had in mind that, when studying the ways their agents became professional and institutionalized, we could detect their approximations and distances (interdependences) from the health field. Although the basic reference is collective health, we extended the research to health professionals in the overall. We understood we would be broadening the research, but the limits of those fields are wide and with boundaries that are not always easily identifiable. Once again, the configuration could be associated to an understanding of health and collective health, if we would study them by themselves. 
In this regard, we had in mind we were facing a study in the field of Elias' procedural sociology, therefore we would need a instrumental support that defined a type of "cartography", in other words, the "place" of social scientists in the interdependent relationship space between social sciences-health-social sciences.

Thus, it seemed to us that the fuzzy logic was proper and dealing with it in a configurational way would not mean a deviation to Elias' sociology, although it is apparently paradoxical.

To better understand the approximation (at the moment this relationship was outlined) of Elias and fuzzy logic, we analyzed some ideas about logic and their application.

Although its fundamental concepts were developed in 1965, by Lotifi A. Zadeh, and its first application was in 1975 in production engineering, Heisenberg raised in 1927 matters related to uncertainty principle that grounded the quantum theory. The repercussion of the fuzzy logic reached many knowledge fields in a growing way. When Zadeh published his work in 1965, he combined the concepts of classical logic and Jan Lukasiewicz (1878-1956), the latter was a pioneer of logic construction of "vague" and "indefinite" concepts in $1920^{7}$.

Fuzzy logic applications have already been spread by many knowledge areas, such as engineerings, medicine and nursing. In health area, it is highlighted its use to model the medical diagnosis process ${ }^{8,9}$ and the scintillographic examination from the result of laboratory exams ${ }^{10}$. The review on the matter in nursing area ${ }^{11}$ establishes its importance as investigation methods and development of models and support systems to decision making on hard technologies.

Among the works that review the relationships between fuzzy logic and social sciences, there is Winter and Kron. In such work, the authors emphasize that logics is applied to those "vague and indefinite social facts" and remind that it is "not only a method, but it implies a new world vision that focus not only the bivalence, but also the polyvalence and, in this regard, it challenges the "probability monopoly" of the classical Aristotelian logic about the world". According to the authors, its application is extended to studies on action theory to social systems. To them, "The theoretical approaches about the actor have to deal with analytical problem, the socalled "situation definition", which is how social actors express themselves in a given social situation. To define the proper bridge hypotheses, social scientists require a method to connect the "environment" of an actor (institutions, norms, values, communication, symbols etc.) to a personal setting of an actor as internalized standards and values, identities, emotions etc. The fuzzy logic seems to be an appropriate method to create such hypotheses because it qualifies social scientists to model the link between situational parameters and personal settings of actors, considering social actors rarely interpret social situations in a completely unequivocal way".

Thus, they emphasize the fuzzy logic application in studying social systems when they state that: "The fuzzy logic allows overcoming the bivalent thought in systems theory. Rather than super emphasizing the bivalence as a stability criterion of social systems, the fuzzy thought forces social scientists to consider vague and indefinite communicational processes within social systems and, therefore, raise the awareness to social mechanisms that allow dealing with social fuzziness. Nowadays, Ulrich Beck is a prominent sociologist who emphasizes the fuzzy thought in modernization theory" ${ }^{1}$.

\section{Studies about health social scientists}

Although there were previous studies about health social scientists, we did not find in the literature an approach using the fuzzy logic. A fast review about those social scientists shows that this preoccupation has been present since its origins in the USA. Straus ${ }^{12}$ researched, in the 1950s, information about 110 sociologists who have worked in health area, probably the first research about such issue. Only in 1961, the American Sociological Association requested to Odin Anderson (1914-2003) a study about who was that medical sociologist ${ }^{13}$. Unfortunately such study did not continue and, in 1962 Rose Laub Coser (1916-1994) and Janice Hopper conducted a survey requested by the American Sociological Association (ASA) to know how many medical sociologists existed. From 854 members contributing to ASA, 382 answered the questionnaire and, among them, $82 \%$ (312) were sociologists, of which 53 had a double identification, either with anthropology, medicine or psychology and 12 of them had a triple identification: Research was the dominant activity ( $85 \%$ of total sample) and 55\% were dedicated to teaching ${ }^{13}$. Those were pioneer studies, and in Brazil there are some researches that tried to characterize the social scientists who work in the health field. A Campos and Nunes' ${ }^{14}$ study showed data of 1971, related to teaching in 168 schools in health area, of which, 85 informed 
to include sciences or social themes. From 323 teachers, only $57(17.6 \%)$ had basic education in the social sciences area. More recently, a research by Nascimento 15 registers a total of 238 social scientists in health area activities.

\section{Innovating the methodology}

Usually, the most used techniques to know who is who in social sciences in health has been the questionnaire and, in case of qualitative studies, the interviews. The use of other secondary sources, such as data bases, especially from $\mathrm{CNPq}$, is less often. Thereby, this work used as ground the résumés of the Lattes Platform, subsidized by information contained in websites of Medicine Universities and Colleges in Brazil and websites of Collective Health Institutes. In websites of Medicine Universities and Colleges and in Research Institutes, we had access to names of professionals and, after consulting the website, we checked, grounded on inclusion criteria, whether or not they were part of the research universe. We collected the following information from the résumés: name; gender; undergraduate; specialization; master's degree; $\mathrm{PhD}$; post $\mathrm{PhD}$; states, countries and institutions where academic education; current work institution; employment relationship; carried out activities; work areas and main research lines were carried out.

Lattes Platform is part of $\mathrm{CNPq}$ and it is formed by résumés of professionals who are visited and analyzed by institutions to foster research, teaching institutions and by the subjects and researchers who feed this great database on individual level, with new information related to their professional career. The other areas of the website are related to Directory of Research Groups and Institutions Directory.

This search was carried out as follows: First, we opted by advanced search, individually selecting the words sociology, anthropology, political science and social sciences and selecting the filters according to education everyone should have $\mathrm{PhD}$. As work area, the professionals should have health sciences as great area and collective area as work area.

The decision to limit the research to professionals with $\mathrm{PhD}$ was made as a result of the research objective, attempting to know the professionals profile with full education which worked in areas of teaching, extension, research and were professionally inserted in any type of institution.

The advanced search with the words sociology, anthropology, political science and social sciences with $\mathrm{PhD}$ and the work area in the great area of health sciences and collective health area generated a total of: 320 names in Anthropology; 552 names in Political Science; 252 names in Sociology and 314 names in Social Sciences, a total of 1438 résumés; the collection was made between March and April 2010.

In order to assure greater validity and reliability to our study, we carried out a search with institutions. We selected institutions throughout national territory from two sites with different characteristics. One of them (www.oestudante. com.br) is directed to the students, especially the one who is taking up admission exams to the university and, during the search, is allowed opting for state and course. The other site (www. universidades.com.br) allows to carry out the search only by universities, but it enables us to have more options, which provides us a greater comprehension and a way to valid the collection without leaving any important institution out of the study. We chose to carry out the search in commercial, unpaid websites, considering that they had the most popular Universities and Colleges among students. In both of them, we decided for a medicine course internal to Medicine Colleges, Collective Health departments or Preventive Medicine and graduation in Collective Health, places where the professionals we seek are in higher number.

Furthermore, we conducted searched in Research Institutes in Health and Collective Health. Such option to collect data through selected institutions was efficient, as we found professionals with resume résumé at the Lattes Platform, with the profile we searched, but who did not mention collective health as work area in any field and were out of the selection we carried out at the Lattes Platform. Such resource allowed us to find and include them in our database. Most names we found in institutions were already selected by the search on the Lattes Platform, showing, thus, the reliability of our collection.

The collection stage on websites took around eight months during the years 2009/2010, where we searched 119 institutions, in a total of 1743 résumés viewed on the Lattes Platform, and we selected 101 of them.

In the total of two searches, of websites and the Lattes Platform, we visited 3181 résumés. We selected a total of 244 résumés, according to inclusion and exclusion criteria. Among the 244 names, some of them did not have résumés at the Lattes Platform, whilst others had died, which ended up totalizing 238 names. The collected 
data were part of a bank at SPSS with all information related to the collected variables described above.

\section{Mapping relationships, building a configuration: The potential of the fuzzy logic}

Grounded on collected data at the Lattes Platform, we checked the variability of professional backgrounds. Even if all professionals had in common any education in the area of social sciences, due to their undergraduate and graduate choice, there were proximities and distances related to Collective Health field and social sciences as work areas.

As our interest was exactly on the professional intersection configuration between Social Sciences and Collective Health, the fuzzy logic system, which essentially reproduces the human reasoning model, in other words, a relative reasoning, enabled us to reach two objectives of our study: 1) Clarifying relationships between those diverse professional choices; and 2) Mapping those relationships related to the field of Collective Health and social sciences, generating a configuration that embodied the approximation and distance degree of those professionals with both areas. Understanding the place of each professional according to his/her choices and their relationship with their peers, embodying where (to which distance) each one is located, would only be possible grounded in a relational methodology.

According to $\operatorname{Cox}^{16}$, adopting the fuzzy logic means to carry out three fundamental operations: fuzzification; inference and defuzzification. We adjusted our study to those stages. In this regard, a text by Aguado and Cantanhede ${ }^{17}$, who work with those stages in a didactic way, was important for this research.

\section{Stage 1 - Fuzzification}

The fuzzification corresponds to the stage where data are transformed into linguistic variables. Thus, we had different possibilities related to undergraduate and graduate education of professionals in different knowledge areas, considering all uncertainties or inaccuracies ${ }^{18,19}$. The possibilities found according to professional backgrounds were described in two typological tables (Table 1 and Table 2).

As a result of necessity to relate such backgrounds to fields of Social Sciences (SS) and Col- lective Health $(\mathrm{CH})$, it was created two new variables (or fuzzy sets) that represent the areas SS (CAss) and $\mathrm{CH}$ (CAch). Thus, we should relate each type of the Typological Table with regard to proximity or distance with both fields, information that denotes the relevance degree (Figure 1).

The relevance function determines the likelihood of each individual to belong to each area related to his/her education in each of three levels (undergraduate, master's degree and $\mathrm{PhD}$ ). The values of those likelihoods are provided by a specialist. Thus, the Social Sciences can value 100 or 90 .

\section{Stage 2 - Inference}

The variability of values provided to each area corresponds to distance or approximation degree related to the area of social sciences and collective health and corresponds to a process referred to as Inference. According to Von Altrock ${ }^{19}$, mentioned by Aguado and Catanhede ${ }^{17}$, such phase can be referred to as Aggregation and Composition. The Aggregation stage corresponds to use

Table 1. Type of professionals and their respective undergraduate and graduate education, starting with social sciences as undergraduate

\begin{tabular}{clc}
\hline Type & \multicolumn{1}{c}{ Education } & Professionals \\
\hline Type 1 & Social Sciences + Social Sciences + Social Sciences & 56 \\
Type 2 & Social Sciences + Social Sciences + Collective Health & 16 \\
Type 3 & Social Sciences + Collective Health + Collective Health & 19 \\
Type 4 & Social Sciences + Social Sciences + Other Areas & 18 \\
Type 5 & Social Sciences + Collective Health + Other Areas & 17 \\
Type 6 & Social Sciences + Other Areas + Other Areas & 2
\end{tabular}

Caption: Social Sciences: it corresponds to social sciences, anthropology, sociology and political sciences. Collective Health: it corresponds to collective health.

Table 2. Type of professionals and their respective undergraduate and graduate education, starting with undergraduate in different areas of social sciences

\begin{tabular}{clc}
\hline Type & \multicolumn{1}{c}{ Education } & Professionals \\
\hline Type 1 & Health Area + Human Sciences + Social Sciences & 15 \\
Type 2 & Health Area + Social Sciences + Collective Health & 13 \\
Type 3 & Health Area + Social Sciences + Health Area & 7 \\
Type 4 & Health Area + Social Sciences + + Social Sciences & 15 \\
Type 5 & Human Sciences + Social Sciences + Collective Health & 9 \\
Type 6 & Human Sciences + Social Sciences + Social Sciences & 40 \\
Type 7 & Others: Human Sciences + Human Sciences + Social & 3 \\
& Sciences/Human Sciences + Social Sciences + Exact/ & \\
& Social Sciences + Exact + Collective Health & \\
\hline
\end{tabular}

Caption: Social Sciences: it corresponds to social sciences, anthropology, sociology and political sciences. Collective Health: it corresponds to collective health. 
of the term If, production of terms that start the inference process. The second stage corresponds to the use of the term $S o$, which defines the result after carrying out the inference. Focusing on our study, both terms translate exactly the relational aspect of choices of undergraduate and graduate courses with the fields of SS and CH.

For instance, If an individual is undergraduate in History, So he/she has a degree of 80 out of 100 belonging to the Area of Social Sciences, whilst another person who has a $\mathrm{PhD}$ in Medicine has 70 out of 100 belonging to Collective Health.

\section{Stage 3 - Defuzzification}

The third and last stage corresponds to translation of two previous stages in a numerical value, in other words, the translation of a fuzzy value in a real number, according to Cox. Thus, it was created two new variables, numerical, deterministic (Not fuzzy), that represent the co-relation of each professional with the SS and $\mathrm{CH}$ areas.

To define the relevance degree of each area, it was added, in a balanced way, the values of each of three education stages, making the defuzzification function a triple entry function (Equations 1 and 2).
ESS $=($ CASS (undergraduate $) \times 1+$ CASS (masters' degree) $\mathrm{x} 1.05+$ CASS $(\mathrm{PhD}) \times 1.1) /$ amount of education (1)

$\mathrm{ECH}=(\mathrm{CACH}$ (undergraduate $) \times 1+\mathrm{CACH}$ (masters' degree) $\mathrm{x} 1.05+\mathrm{CACH}(\mathrm{PhD}) \times 1.1) /$ amount of education (2)

The ESS and ECH values are Vectors of Relevance Degree of each of two interest areas in this study ( $\mathrm{SS}$ and $\mathrm{CH}$ ) and they were added to the database as two new columns.

From the created ESS and ECH variables, and with the objective of making data operational and representing the "cartography" of social scientists who work in the health area, according to the logic of relational networks of Norbert Elias, we used the cluster package of statistical software $\mathrm{R}$. Through such software, it is possible to calculate the Fanny function that defines vectorial distances between professionals related to two axes represented by Ess and Ech variables and classify them in clusters. The amount of clusters used (6) was set out according to typology empirically observed. The graphic representation of clusters was obtained through clusplot function, required as tool to analyze the co-relation between clusters and their composition and the areas of Social Sciences and Collective Health.

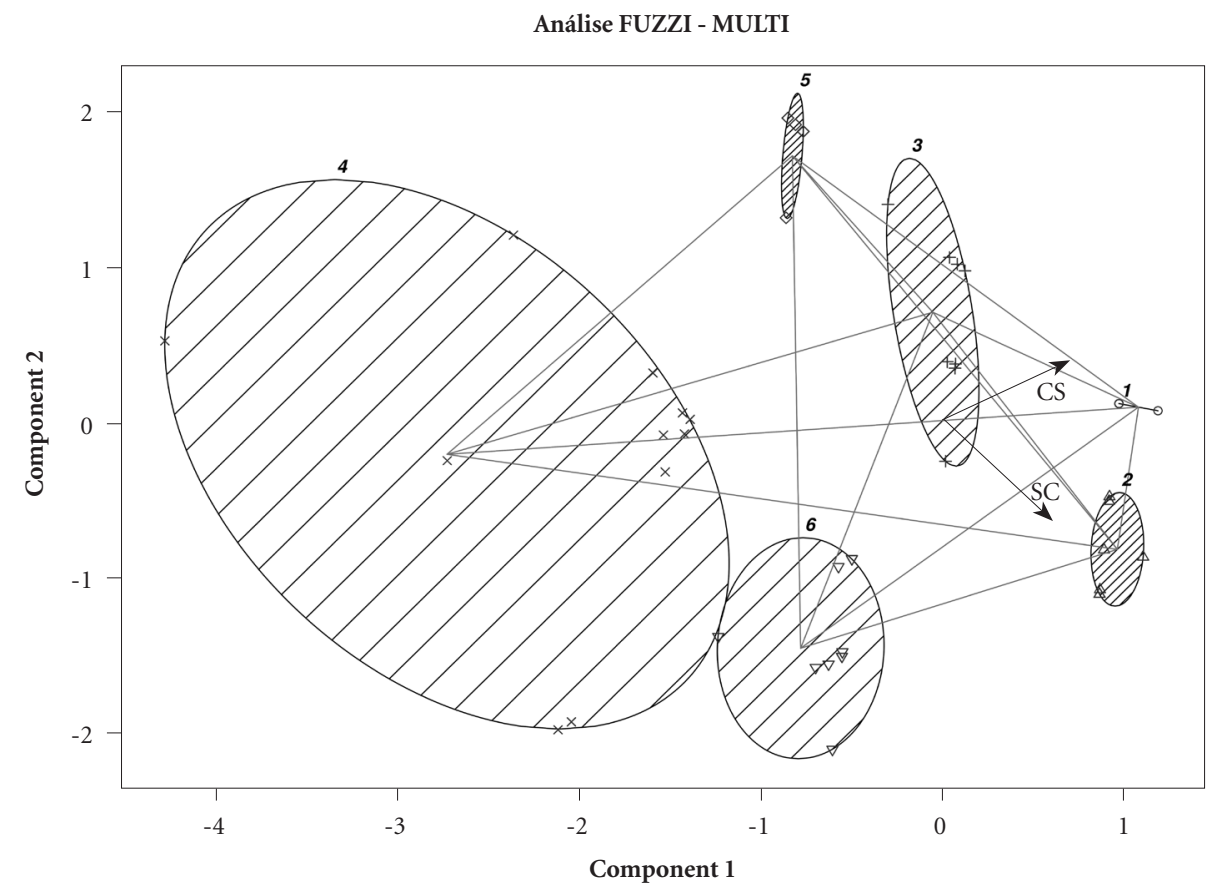

These two components explain $100 \%$ of the point variability

Figure 1. Configuration of a field: Graphic representation of cluster and their relational networks. 
We submit the results obtained in this study, which allow us to visualize the configuration. The figure composition brings the different groups, formed with undergraduate and graduate education and their relationships with other groups. Each group or cluster has its own specificities which makes it unique and represents a group of professionals and their co-relations with the area of social sciences and collective health (Figure 2).

Cluster 1 is located near the corresponding vector (red arrows) of social sciences and represents the group with greater linearity in its education, with 42 undergraduates in social sciences and most of them have both undergraduate and graduate education in social sciences. As a result of its homogeneity, the space occupied by such cluster is very small, related to other ones, although having a greater concentration of professionals (58). Such cluster is mostly formed by women (45), denoting a gender specificity in professional education choice, related with studies that affirm the relationship between choices of professional areas and gender ${ }^{20,21}$. This tendency of human sciences and health areas concentrated more women than men is related to what Velho and Léon ${ }^{22}$ referred to as gender tracking or concentration of women in specific subjects and is related to socialization of different social roles. There is a representative number of professionals connected, in states of São Paulo (20) and Rio de Janeiro (15), to public institutions, such as UNIFESP, Unicamp and Public Health School of USP, Fiocruz and UERJ. Such fact highlights the concentration of resources of state and federal governments in South and Southeastern regions, in addition to be defined as the main places that produce knowledge. According to the National Plan for Graduate Studies 2005-201023, up to 2003 the distribution of graduate programs in different Brazilian regions was unequal. The Southeastern region concentrated $54.9 \%$ of masters' degrees and 66\% of PhDs. The Southern region totalized $19.6 \%$ of master degrees and $17.1 \%$ of PhDs. The Northern region totalized $15.6 \%$ and $10.3 \%$, respectively. Midwest had $6.4 \%$ and $4.1 \%$, and Northern region had 3.5\% of masters' degrees and $1.8 \%$ of $\mathrm{PhD}$. We have experienced nowadays a considerable increase in graduate programs specifically in collective health, and $66.3 \%$ of them are in Southeastern region $^{24}$.

In our research, of the total of 58 professionals, 27 of them identify themselves as working in anthropology area and 14 in sociology, only 10 mention collective health as their work area, even if institutionalized in School of health area or Collective Health Departments, Preventive and Social Medicine or Research Institutes of health area. Such fact emphasizes the importance of professional education background as the bases of professional identity that often exceeds the professional institutionalization.

Cluster 2 concentrates a total of 38 subjects, 26 of them are female and 12 are male, including professionals with education in social sciences and collective health. Such professionals represent exactly the intersection between both areas in professional education choices. Located near the end of the vector of collective health, as a result of greater number of professionals with two educations in collective health other than with one education in collective health and two in social sciences, this group is places closer to collective health, in addition to have a greater space comprehension, exactly due to variance of combina-

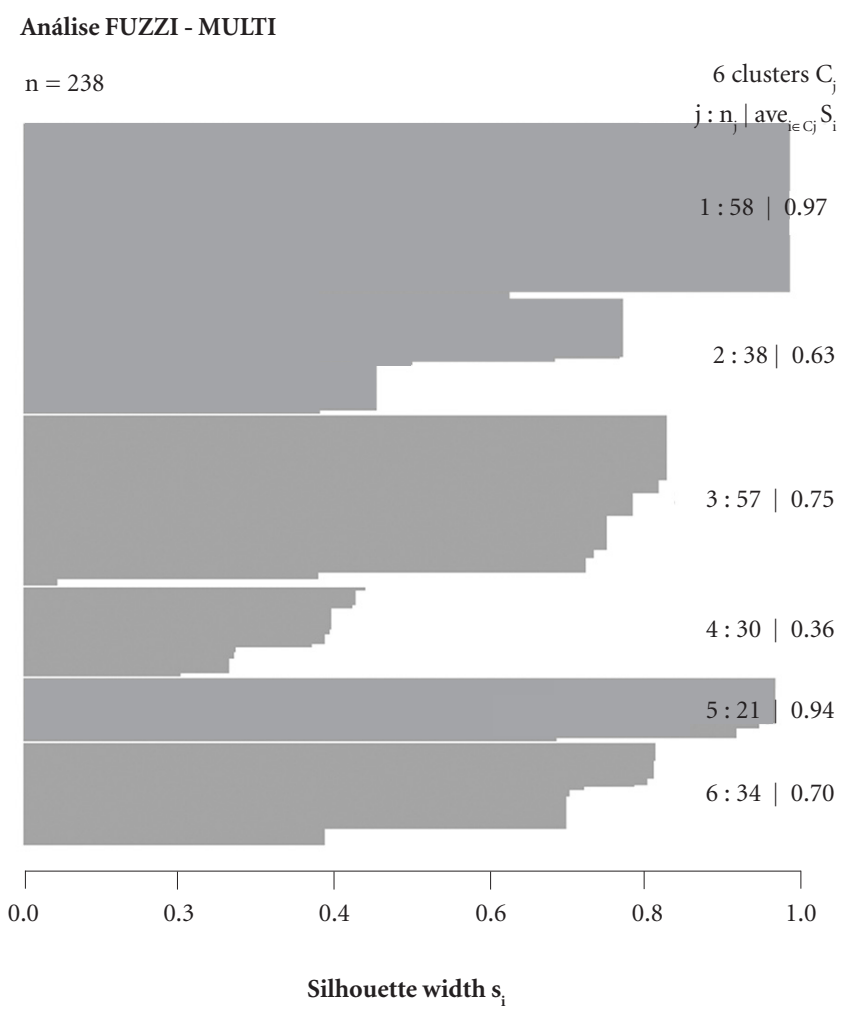

Average silhouette width : 0.74

Figure 2. Configuration of a field: Numerical clusters composition. 
tions. Because they are greater to the collective health vector, the importance of education related to work area is reinforced, as 25 professionals mention collective health as their work area.

Cluster 3 is formed by 57 subjects, 36 of them are female and 21 are male, mostly formed by professionals with education in areas of human sciences and social sciences and, in smaller number, with education in social sciences and collective health. As a result of its composition, cluster 3 has an elliptical form to comprehend the human sciences area, which is closer to social sciences than to collective health, but with some professionals with education in collective health, which justifies its form, its approximation of SS component vector and relative approximation of collective health. The institutionalization is remarkable in the state of Rio de Janeiro, and more than half of professionals who work in this state are part of Fiocruz. Such cluster represents smaller differentiation between professionals and respective work areas and 12 of them are related to anthropology, 19 to collective health and 13 to sociology.

Cluster 4 is representatively the greatest one, not due to concentration (30), but as a result of its heterogeneity, including a greater space related to different approximations and distances from the two vectors. The cluster corresponds to professionals with education in social sciences and two in different areas, such as, for instance, undergraduate in social sciences and graduate in information science, a reality that places him/her very distant from collective health and, despite closer to social sciences, with regard to other professionals he/she is very distant, representing this cluster the example of greater possible distance of both areas (social sciences and collective health). It has a low number of undergraduate students in social sciences (5) and existence of undergraduate of other areas, such as physics, medicine (9), civil engineering, pharmacy, nursing and occupational therapy. The professional multiplicity is also represented in multiple states where they are distributed, without discrepancies related to number by state in institutions such as Fiocruz, UFBA, UFMG, UFC, UFRGS and USP. It is represented by 14 male professionals and 16 female.

Cluster 5 corresponds to the group of smaller difference between male (10) and female (11), totalizing 21 professionals with education mainly in psychology, economics, social service and philosophy. The professionals are equally distributed in institutions of different states, such as Paraná, Rio Grande do Sul, São Paulo and Distrito Federal. With regard to research lines, the profession- als work with different subjects, such as mental health, occupation, violence, alcoholism, primary attention.

Of the total of professionals, five mention collective health as their main education area and five mention psychology as their main work area.

Cluster 6 is formed by 34 professionals, 22 of them are female and 12 are male with, at least, one education in health area, in areas such as nutrition, odontology and most of them in medicine (15). The professionals are spread among different states, such as Ceará, Alagoas, Bahia, Pernambuco, most of them are in Rio de Janeiro (8), more specifically at Fiocruz, UFBA, Unifesp, but none of them at USP. They work with different subjects, especially with gender and sexuality (5) and indigenous population (6), subject lines both acknowledged and made legitimate by the field of social sciences, more specifically anthropology. It is interesting to emphasize the configuration of research lines of this cluster, when we relate them to education of professionals who are part of this group who, although most of them have undergraduate in health area and only three in social sciences, eight have masters' degree and 12 of them have $\mathrm{PhD}$ in anthropology. Thus, anthropology is an extremely important area of social sciences to configure such cluster and has an intersection point between social sciences and collective health. A great number, 20 of them, mentioned collective area as work area, which corresponds to a difference compared with cluster 5 , where, as it was previously described, there is an entirety of people with education in human sciences areas and a low number of professionals who mentioned collective health as work area, an interesting element for us to reflect about the undergraduate importance to built up professional identity.

According to Elias, both social and individual habits are mutually related and built up. Grounded on analysis of clusters and their internal configurations, we could relate undergraduate, masters' and $\mathrm{PhD}$ courses choices, in other words, professionalization backgrounds of professionals and research lines or work areas mentioned by them. Moreover, we could also visually show the relationship between individual choices and construction of cluster (group) and their graphic relationship with social sciences and collective health, in other words, with general configuration of field.

Grounded in the Elias' concept of relational networks, the structuring axis of work, the fuzzy logic analysis embodied such concept upon en- 
abling the definition of relationships between individuals and their respective groups (clusters).

According to Elias ${ }^{5}$, “(...) the network is only understandable in the way they are connected, according to their reciprocal relationship. This relationship originates a system of tensions to which each isolated wire contributes, each one in a slightly different way, according to their place and function in the entire network. The form of individual wire is modified when the tension and structure of the entire network are changed. Nevertheless, this network is nothing but a connection of individual wires, and inside it each wire continues to consist in a unit itself with a position and singular form inside it".

Starting in the second half of the XX century, the concept of network becomes fundamental for sociologic theory, consolidating it as a specific field called sociology of networks, built grounded in two doctrines; 1) British social anthropology, after World War II, by analyzing limit groups and attempting to distance from classic functional structural model, and 2) A quantitative and structural analysis of American doctrine ${ }^{25}$. The great leap of networks theory consists in analyzing the social structure from a relational perspective, removing the focus from the individual or society as single categories, and conceiving them as reflections of structural relationships existing between the individuals and composition of their social group and that, therefore, have historicity, mutability and an always relational existence.

On the one hand, the fuzzy logic allowed to visualize the configuration of field, Elias' approach showed reciprocal dependence between the individuals and their groups, which are connected by individual links, work, property of intellectual goods, affections, disagreements, creating an inter dependency network among individuals. Actually, this is the crucial point of this work -relational networks formed by social scientists in the collective health field.

Studying those networks, grounded in their professional background, allowed us to observe that their undergraduate and graduate choices are very important, and giving them an identity that ends up meaning choices of research themes and the option to identify themselves in social sciences areas or collective health as their work area, as we described in the clusters above.

If we analyze clusters 1 and 2, grounded in networks theory, it is clear that their configuration reflects the relationships. Cluster 1 represents the greatest number of social scientists, located closer to the vector of social sciences and their actors mention social sciences as work field. Cluster 2 represents most professionals with two undergraduate and graduate educations in collective health and one in social sciences, most of them mention collective health as work area. And, in both of them, the professionals institutionalize themselves in collective health area. Such description allows us to emphasize two fundamental principles of networks theory: Firstly, that actors and actions (in this case, professional choices) are interdependent and, secondly, the relational ties among them are channels with flows of resources, such as, for instance, the production and sharing production of specific knowledge of the fields that they form and reproduce. In the case of both clusters, we can infer that there is a great interconnection between actors, as a result of their density and similarity, which allows greater flow of resources, information and shares standards, being a specific individual and social habit. Thus, sub groups are similar among themselves, forming their relational networks that are related with other sub groups, presenting the configuration shown in Figure 1, which is dependent of all existing relational networks.

\section{Final considerations}

We should reflect on some important points on this study. First, turning the Lattes Platform, in the case of professionals' résumés, an important research material and that is available to scholars. In such study, we did not use this material in all its extension, but what was necessary to our objectives. Second, making the fuzzy logic a valuable instrument to studies in social sciences field and showing it brings a relevant quantitative approach for those studies. Third, not less relevant, basing on Norbert Elias' powerful references, and exemplifying its adequacy to studies in collective health field, which is something that can be broadened and diversified in other studies.

We were able to answer many questions with theoretical references and methodological choices made throughout the study, while other questions remain open, as it is a quantitative study and it ended up generating the necessity of a greater qualitative depth. But it became possible to generate a profile of professionals with education in social sciences and who are part of collective health field; knowing the importance of professionalization path to build up professional identity, not being a identity migration, as it is a multidisciplinary field, but exactly what 
networks theory informs us: The relational importance between actors and their actions, in other words, the process through which the professional identity is built. We could also confirm that collective health is a hybrid field exactly due to multiplicity of different subject areas in the education of professionals. In this fields there are people undergraduate in health areas and graduate in social sciences, as it was evident in cluster 6; or cluster 4 , which is representatively the greatest one, however it is the most heterogeneous with professionals with education in physics or engineering and with the smallest number of professionals graduate in social sciences, representing the most distant group of collective health and social sciences, but which is also part of the field and such difference takes place through a configuration of the network itself. Grounded in Elias' theory and fuzzy logic, we were able to build a methodological possibility to analyze a knowledge field and graphically represent the relationship between sub groups, and their relational networks allowed us to know and visualize both micro and macro universal that configures this professional group in a unique way. Specially, we could confirm that collective health is a hybrid field exactly due to multiplicity of different subject areas in the education of professionals.

\section{Collaborations}

JL Nascimento, C Stephan and ED Nunes equally participated of all preparation stages of this article.

\section{Acknowledgements}

We would like to thank CNPq (National Council of Scientific and Technological Development) for supporting and providing clarifications on how to use the Lattes Platform during this research. 


\section{References}

1. Winter L, Kron T. Fuzzy thinking in sociology. In: Seising R, editor. Views on fuzzy sets and systems from different perspectives: philosophy and logic, criticisms and applications. Berlin: Springer; 2009. p. 301-320.

2. Bomeny H, Birman P. As assim chamadas ciências sociais. Rio de Janeiro: Relume-Dumará; 1991.

3. Corcuff $\mathrm{P}$. As novas sociologias - construções da realidade social. Bauru: Editora EDUSC; 2001.

4. Elias N. Introdução à sociologia. Lisboa: Edições 70; 1970.

5. Elias N. A sociedade dos indivíduos. Rio de Janeiro: Jorge Zahar Editor; 1994.

6. Fundação Getúlio Vargas (FGV). Dicionário de Ciências Sociais. Rio de Janeiro: FVG; 1987.

7. Zadeh LA. Fuzzy sets. Information Control 1965; 8:338353.

8. Gomes LT, Barros LC Aplicação de Lógica fuzzy em diagnóstico médico a partir de medidas de proteínas. [acessado 2011 nov 30]. Disponível em: http://www. ime.unicamp.br/ biomat/res/lutakata_r.pdf

9. Barreto MMG, Balbionto A. Modelagem fuzzy possibilidade de conhecimento médico. [acessado 2011 nov 30]. Disponível em: http://www.lume.ufrgs.br/bitstream/handle/10183/30411/000730998.pdf?sequence $=1$

10. Souza CA, Duarte S, Pereira JCR. Lógica fuzzy e regressão logística na decisão para prática de cintilografia das paratiróides. Rev Saude Publica 2006; 40(5):898-906.

11. Jensen R, Lopes MHBM. Enfermagem e lógica fuzzy: uma revisão integrativa Rev. Latino-Am. Enfermagem 2011; 19(1):195-202.

12. Straus $R$. The nature and status of medical sociology 1957. Amer Soc Rev 22(2):200-2004.

13. Bloom SW. Word as scalpel: a history of medical sociology. New York: Oxford University Press; 2002.

14. Campos RZ, Nunes ED. O ensino das ciências sociais nas escolas profissionais da área da saúde no Brasil. Rev Saude Publica 1976; 10(4):383-390.

15. Nascimento JL. Uma (con)figuração: cientistas sociais, antropólogos, sociólogos e cientistas políticos em saúde no Brasil [tese]. Campinas: Universidade Estadual de Campinas; 2011.
16. Cox E. The fuzzy systems handbook: a practitioner's guide to building, using, and maintaining fuzzy systems. New York: AP Professional; 1994.

17. Aguado AC, Cantanhede MA. Lógica fuzzy. [acessado 2012 dez 8]. Disponível em: http://www.ft.unicamp.br/ liag/wp/monografias/monografias/2010_IA_FT_UNICAMP_logicaFuzzi.pdf

18. Jané DA. Uma introdução ao estudo da lógica fuzzy. Hórus 2004; 2:1-16.

19. Von Altrock C. Fuzzy logic and neuro Fuzzy applications in business and finance. New Jersey: Prentice Hall PTR; 1996.

20. Machado MCS. A feminização da medicina. Análise Social 2003; XXXVIII(166):127-137.

21. Agência Brasil. Iniciação tecnológica. [acessado 2010 jun 20]. Disponível em: www.inicacaotecnologica.com. $\mathrm{br} /$ noticia/noticia.php?noticia=encontro-discuteparticipacao-mulheres-ciencia

22. Velho L, Léon E. A construção social da produção científica por mulheres. Cadernos PAGU 1998; 10:309-344.

23. Plano Nacional de Pós-Graduação (PNPG) - 2005-2010. Resumo Executivo. Brasília. RBPG 2005; 2(3):185-198.

24. Barata RB. A pós-graduação e o campo da saúde coletiva. Physis 2008; 18(2):189-214.

25. Portugal S. Contributos para uma discussão do conceito de rede na teoria sociológica. 2007. [acessado 2014 jul 1]. Disponível em: http://www.ces.uc.pt/publicacoes/ oficina /ficheiros/271

Article submitted 28/08/2014

Approved 25/09/2014

Final version submitted 27/09/2014 
